\title{
Exploiting the allelic polymorphism at microsatellite loci to underpin the genetic status of Cirrhinus mrigala in wild populations
}

\author{
Hina Amjad and Khalid Abbas* \\ Aquaculture Biotechnology Laboratory, Department of Zoology, Wildlife and Fisheries, University of Agriculture, \\ Faisalabad-38040, Pakistan \\ *Corresponding author’s e-mail: dr.abbas@uaf.edu.pk
}

\begin{abstract}
An adequate knowledge regarding the genetic issues of natural populations is imperative for developing conservation and stock improvement plans. The present research work was aimed to assess the genetic variability and structuring patterns in six natural populations of Cirrhinus mrigala from Punjab province, Pakistan. The PCR based amplification of targeted loci was carried out by employing a total of 12 microsatellite markers. Based on the study inferences, moderate level of genetic diversity was observed in all the populations. The average number of alleles $(\mathrm{Na})$ varied from 3.750 to 4.416 and those of effective number of alleles ranged between 3.112 to 3.856 in all the examined populations. The mean values of observed and expected heterozygosity were measured as 0.563 to 0.685 and 0.669 to 0.739 , respectively. The average values of inbreeding coefficient $\left(F_{I S}\right)$ ranged from 0.019 to 0.184 . Significant deviation from $H W E$ was detected in 9 out of 72 tests. Among all the population pairs, low to moderate level of genetic differentiation was found. After applying AMOVA, it was revealed that most of the variations $(81.15 \%)$ lied within individuals. The UPGMA dendrogram resulted in two distinct clusters. The present study inferences would be helpful for setting up effective strategies to avoid the loss of genetic variability in C. mrigala populations.
\end{abstract}

Keywords: Genetic diversity, population differentiation, molecular markers, riverine populations.

\section{INTRODUCTION}

Study of population genetics explores the allocation of genetic variations at various scales in populations. Genetic variability is primarily affected by the forces of selection, mutation, migration and random genetic drift. The patterns of genetic variability between different populations give effective clues about the life histories and degree of evolutionary isolation (Ciftci and Okumus, 2002). Genetic diversity is imperative for the long term survival of the species as it assures the fitness of species by providing the potential to survive under varying environmental conditions as well as natural selection pressure (Banerjee et al., 2008). However, due to human interventions, poor management and lack of rehabilitation programs the genetic diversity of commercially important fish species is being devastated (Abbas et al., 2010). Therefore, the assessment of genetic diversity and structure of fish stocks after few generations is indispensable to maintain a diverse gene pool for the better conservation and sustainable management of valuable fish species (Ciftci and Okumus, 2002).
The fish Mrigal, Cirrhinus mrigala is an economically important and culturable freshwater carp, native to the Indus riverine system of Pakistan, Bangladesh, Myanmar, Thailand and India. This species has also been successfully introduced from its natural range to other countries like China, Japan, Malaysia and Vietnam. It is highly preferable fish to be cultured under polyculture systems because of its aquaculture potential, consumer preference and high compatibility with other major carps such as Labeo rohita and Catla catla (FAO, 2006). The aquaculture production of this species was over 573,624 metric tons, contributing $1.6 \%$ of total world fish production (FAO, 2004). However, in recent years this species showed a declining trend in wild capture fisheries and natural genetic resources due to anthropogenic interventions. Therefore, some effective measures are necessary for the conservation of the genetic integrity of this species.

In most natural water systems, gene flow and the dispersal of species are the two key components with strong influence on the evolution and demography of spatially structured populations. The genetic structure of any population is strongly influenced by gene flow, genetic drift as well as selection pressure (Banks et al., 2013). Maintaining the

Amjad H. and K. Abbas.2021. Exploiting the allelic polymorphism at microsatellite loci to underpin the genetic status of Cirrhinus mrigala in wild populations. Pak. J. Agri. Sci. 58:1349-1357.

[Received 1 Mar 2021; Accepted 1 Jul 2021; Published (online) 21 Sep 2021] 
genetic variability and gene flow through the spread of locally adapted genes enables the populations to respond effectively to changing ecological conditions. The timing and rate of these changes may be more rapid than the potential adaptive response by the organisms possibly increasing the risk of extinction of local populations particularly for those species which have restricted movements within the riverine systems that are highly vulnerable to fragmentation (Kawecki and Ebert, 2004).

The interspecific genetic divergence through the analysis based on molecular markers provides accurate information regarding phylogenetic relations and also helps to resolve taxonomic obscurities (Rocha-Olivares et al., 2000; Backer et al., 2002; Rasmussen et al., 2003). Among the available array of DNA markers, microsatellite DNA markers proved to be powerful tools because of their high degree of polymorphism, co-dominant nature, high rate of mutation, small locus size, abundance in genome and the relative ease of application. In fisheries genetics, these markers have been extensively used to study population genetic structure, loss of genetic variability in natural and hatchery populations as well as to plan effective breeding programs for the improvement and restoration of species in decline (Abdul-Muneer, 2014). The aim of this study was to evaluate the level of genetic variability and genetic differentiation in riverine populations of C. mrigala.

\section{MATERIALS AND METHODS}

Fish sampling: A total of 210 individuals ( 35 individuals per population) of the proposed fish i.e., C. mrigala were collected from six natural sites (important fisheries points of River Indus basin) of Punjab province, Pakistan. The riverine populations were sampled from Baloki Headworks located on River Ravi (BHW), Khanki Headworks located on River Chenab (KHW), Trimmu Headworks located on River Jhelum/Chenab (THW), Sulemanki Headworks located on River Sutlej (SHW), Chashma Barrage located on River Indus (CB) and Taunsa Barrage located on River Indus (TB) (Fig. 1). After sampling, fish specimens were identified by their morphological features and named according to their site codes. The specimens were placed in tagged polythene bags and preserved in crushed dry ice boxes for transportation to the laboratory where they were stored at $-20^{\circ} \mathrm{C}$.

DNA isolation and quantification: The genomic DNA was isolated from frozen muscle tissues by following the

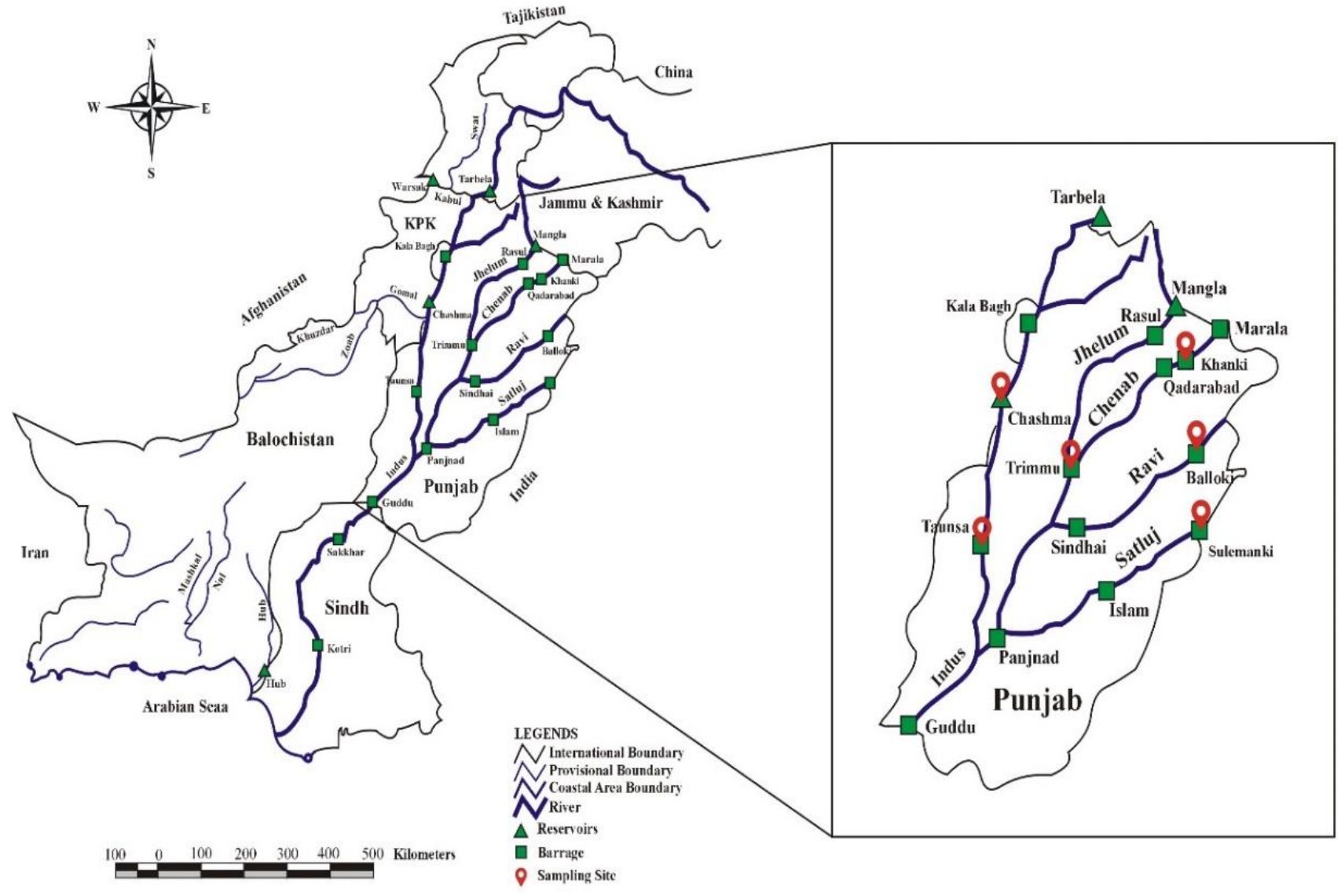

Figure 1. Map showing the riverine sampling sites of $C$. mrigala from Punjab province, Pakistan 
Proteinase-K and standard Phenol/Chloroform/Isoamyl alcohol method of Sambrook and Russel (2001) with slight modifications. The agarose gel electrophoresis (0.8\%) incorporated in TAE buffer with bromophenol blue as loading dye was conducted to confirm the quality of isolated DNA and the concentration of DNA was checked by using NanoDrop at $260 \mathrm{~nm}$ (Thermo Scientific).

Microsatellite loci amplification: The targeted microsatellite loci were cross amplified by using 12 primer pairs developed for Labeo rohita (Das et al., 2005, Sr. no. 1-9) and Cyprinus carpio (Lal et al., 2004, Sr. no. 10-12). The characteristics of each primer pair are given in Table 1. The PCR amplification was accomplished in a $20 \mu \mathrm{L}$ reaction mixture, comprised of DNA template $(50 \mathrm{ng}), 10 \mathrm{X}$ reaction buffer $(1 \mu \mathrm{L})$, each of the dNTPs $(0.25 \mu \mathrm{M})$, each of the primer $(2 \mu \mathrm{M}), \mathrm{MgCl}_{2}(1.5$ $\mathrm{mM}$ ) and Taq polymerase (1 unit) by using the gradient thermal cycler (Multigene Optimax, Labnet USA). The initial DNA denaturation temperature was kept $94^{\circ} \mathrm{C}$ for 3 minutes following 35 cycles at $94^{\circ} \mathrm{C}$ for 30 seconds, at primer specific annealing temperature for 30 seconds and final elongation at $72^{\circ} \mathrm{C}$ for 5 minutes.

Electrophoretic separation of the amplified products and visualization: The amplified PCR products were resolved on $8 \%$ non-denaturing polyacrylamide gel electrophoresis containing acrylamide: bis-acrylamide, stained and visualized following the silver-staining protocol (Sanguinetti et al., 1994). The gel imaging was done in the gel documentation system (Major Science, USA) and the genotypic data was obtained by allelic scoring of gel images with reference to standard DNA ladder (Thermo Fisher Scientific, USA).

Data analysis: The obtained allelic data was analyzed with specialized data packages to infer the different parameters of fish population genetics. The genotypic data was analyzed in Micro-Checker for indicating any scoring errors related to large alleles, stuttering bands and null alleles (Oosterhout et $a l ., 2004)$. The number of alleles $(\mathrm{Na})$, effective allele number (Nae), observed heterozygosity $\left(H_{o}\right)$, expected heterozygosity $\left(H_{e}\right)$ and deviation from Hardy-Weinberg equilibrium $(H W E)$ at each locus was estimated by using POPGENE Version 1.31 (Yeh et al., 1999).

Genetic differentiation among populations was assessed through $F_{s_{T}}$ (Weir and Cockerham's, 1984). The program FSTAT Version 2.9.3.2 was used to calculate allele frequency, allelic richness and inbreeding coefficient (Goudet, 2002). The UPGMA dendrogram based on Nei's (1972) unbiased distance was constructed with the help of TFPGA Version 1.3 (Miller, 1997). The analysis of molecular variance (AMOVA) was conducted by using ARLEQUIN, Version 3.1 (Excoffier et al., 2005). The evidence for genetic bottleneck was tested under infinite allele model (IAM), two-

Table 1. Characteristics of microsatellite loci for C. mrigala

\begin{tabular}{|c|c|c|c|c|c|}
\hline Sr. No. & Locus & $\begin{array}{l}\text { Repeat } \\
\text { Unit }\end{array}$ & Primer Sequence $\left(5^{\prime}-3^{\prime}\right)$ & $\begin{array}{c}\text { GenBank } \\
\text { accession number }\end{array}$ & Ta $\left({ }^{\circ} \mathbf{C}\right)$ \\
\hline 1 & Lrl & (TG)14 & $\begin{array}{l}\text { F-GACCCTTAACCCTTGACCTT } \\
\text { R-TGGGATAATGCAGGGAAAAC }\end{array}$ & AJ507518 & $58^{\circ} \mathrm{C}$ \\
\hline 2 & Lr3 & (TG) 19 & $\begin{array}{l}\text { F-ATCTGGCTGCCTATTCACC } \\
\text { R-CATCGGCGACTGCACTGGA }\end{array}$ & AJ507520 & $58^{\circ} \mathrm{C}$ \\
\hline 3 & Lr6 & (TG) 16 & $\begin{array}{l}\text { F-TATCCTGGCTGAAAACTTTG } \\
\text { R-CCCCTACAGGAACAACCAT }\end{array}$ & AJ507522 & $56^{\circ} \mathrm{C}$ \\
\hline 4 & Lrlo & $(\mathrm{CA}) 13$ & $\begin{array}{l}\text { F-GATCTTCAGCGCCAGCGTG } \\
\text { R-GAGGACCTGCCCAGCATG }\end{array}$ & AJ507523 & $60^{\circ} \mathrm{C}$ \\
\hline 5 & Lr12 & $(\mathrm{CA}) 13$ & $\begin{array}{l}\text { F-CACCGCTGCTGTCCATCA } \\
\text { R-AGGTCGGCCAGATACACG }\end{array}$ & AJ507524 & $58^{\circ} \mathrm{C}$ \\
\hline 6 & $\operatorname{Lr} 20$ & $(\mathrm{CA}) 9$ & $\begin{array}{l}\text { F-GCCCGCTGCCGTCTGAC } \\
\text { R-CAATAACTCAGCATGTGGAG }\end{array}$ & AJ831435 & $58^{\circ} \mathrm{C}$ \\
\hline 7 & $\operatorname{Lr} 21$ & $(\mathrm{CA}) 11$ & $\begin{array}{l}\text { F-GATCAGAGGGTCAATGTGG } \\
\text { R-CAGCAGAGTACTATGGAAGA }\end{array}$ & AJ831436 & $58^{\circ} \mathrm{C}$ \\
\hline 8 & Lr23 & (TG) 12 & $\begin{array}{l}\text { F-GGAAATTACAAATGTGCTGATG } \\
\text { R-AGCGCTGCTGTCACTTCTGT }\end{array}$ & AJ831437 & $60^{\circ} \mathrm{C}$ \\
\hline 9 & $\operatorname{Lr} 24$ & (TG) 17 & $\begin{array}{l}\text { F-CAAGGCCAAAAGTGTCCAT } \\
\text { R-AGGAAATTGGTAAAGTGTTTC }\end{array}$ & AJ831438 & $56^{\circ} \mathrm{C}$ \\
\hline 10 & $M F W 1$ & (CA) & $\begin{array}{l}\text { F-GTCCAGACTGTTCATCAGGAG } \\
\text { R-GAGGTGTACACTGAGTCACGC }\end{array}$ & EF144118 & $57^{\circ} \mathrm{C}$ \\
\hline 11 & $M F W 2$ & (CA) & $\begin{array}{l}\text { F-CACACCGGGCTACTGCAGAG } \\
\text { R-GTGCAGTGCAGGCAGTTTGC }\end{array}$ & EF144119 & $55^{\circ} \mathrm{C}$ \\
\hline 12 & $M F W 17$ & (CA) & $\begin{array}{l}\text { F-CAACTACAGAGAAATTTCATC } \\
\text { R-GAAATGGTACATGACCTCAAG }\end{array}$ & EF144122 & $51^{\circ} \mathrm{C}$ \\
\hline
\end{tabular}

Where $\mathrm{F}=$ forward primer, $\mathrm{R}=$ reverse primer, $\mathrm{Ta}=$ specific annealing temperature of the respective primer pair 
phase model (TPM) and stepwise-mutation model (SMM) by sign and Wilcoxon test using the BOTTLENECK program (Piry et al., 1999).

The STRUCTURE Version 2.3.2 was used to analyze the population genetic structure (Pritchard et al., 2000; Falush et $a l ., 2003$ ) by using a burn-in length of 50,000 to 100,000 Monte Carlo-Markov Chain (MCMC) iterations. For each K value, five independent runs were conducted and the number of genetic clusters were specified according to Evanno et al. (2005) with STRUCTURE HARVESTOR (Earl and Vonholdt, 2012).

\section{RESULTS}

Genetic diversity: The indices of genetic diversity for each riverine population have been summarized in Table 2 . In the present study, all the examined microsatellite loci were found to be polymorphic in all the populations. There was no evidence of scoring errors related to large alleles, stuttering bands and null alleles at all the screened microsatellite loci. The allelic size was observed in the range from 144-252 bp and the number of alleles varied from 2 to 8 at the various loci analyzed. The average number of alleles $(\mathrm{Na})$ varied from

Table 2. Microsatellite loci based genetic diversity in the wild populations of $C$. mrigala

\begin{tabular}{|c|c|c|c|c|c|c|c|c|c|c|c|c|c|c|}
\hline \multirow[t]{2}{*}{ Populations } & \multirow{2}{*}{ Parameters } & \multicolumn{12}{|c|}{ Loci } & \multirow[t]{2}{*}{ Average } \\
\hline & & LrI & $L r 3$ & Lr6 & $\operatorname{Lr10}$ & Lr12 & Lr20 & Lr21 & $L r 23$ & $L r 24$ & $M F W 1$ & $M F W 2$ & $M F W 17$ & \\
\hline \multirow{8}{*}{ BHW } & $\mathrm{Na}$ & 2.000 & 5.000 & 3.000 & 5.000 & 5.000 & 4.000 & 5.000 & 3.000 & 5.000 & 3.000 & 4.000 & 4.000 & 4.000 \\
\hline & $A r$ & 2.000 & 5.000 & 3.000 & 5.000 & 5.000 & 4.000 & 5.000 & 3.000 & 5.000 & 3.000 & 4.000 & 4.000 & 4.000 \\
\hline & Nae & 1.789 & 4.231 & 2.906 & 4.076 & 4.351 & 3.629 & 4.512 & 2.913 & 4.246 & 2.892 & 3.035 & 3.245 & 3.485 \\
\hline & $\mathrm{Ho}$ & 0.485 & 0.628 & 0.514 & 0.628 & 0.485 & 0.600 & 0.571 & 0.542 & 0.657 & 0.571 & 0.571 & 0.514 & 0.563 \\
\hline & $\mathrm{He}$ & 0.447 & 0.774 & 0.665 & 0.765 & 0.781 & 0.735 & 0.789 & 0.666 & 0.775 & 0.663 & 0.68 & 0.701 & 0.703 \\
\hline & 1-Ho/He & -0.085 & 0.189 & 0.228 & 0.18 & 0.380 & 0.184 & 0.276 & 0.186 & 0.152 & 0.139 & 0.161 & 0.267 & 0.188 \\
\hline & $F_{I S}$ & -0.086 & 0.169 & 0.23 & 0.181 & 0.382 & 0.186 & 0.279 & 0.187 & 0.135 & 0.141 & 0.162 & 0.244 & 0.184 \\
\hline & PHWE & $0.604^{\mathrm{NS}}$ & $0.012^{\mathrm{NS}}$ & $0.013^{\mathrm{NS}}$ & $0.027^{\mathrm{NS}}$ & $0.000^{*}$ & $0.082^{\mathrm{NS}}$ & $0.005^{\mathrm{NS}}$ & $0.169^{\mathrm{NS}}$ & $0.021^{\mathrm{NS}}$ & $0.000^{*}$ & $0.067^{\mathrm{NS}}$ & $0.000^{*}$ & ----- \\
\hline \multirow{8}{*}{ KHW } & $\mathrm{Na}$ & 2.000 & 5.000 & 3.000 & 5.000 & 4.000 & 4.000 & 6.000 & 4.000 & 7.000 & 2.000 & 4.000 & 4.000 & 4.166 \\
\hline & $A r$ & 2.000 & 4.971 & 3.000 & 5.000 & 4.000 & 4.000 & 6.000 & 4.000 & 7.000 & 2.000 & 4.000 & 4.000 & 4.164 \\
\hline & Nae & 1.724 & 3.293 & 2.806 & 4.605 & 2.941 & 3.792 & 4.382 & 3.315 & 5.361 & 1.581 & 3.592 & 3.673 & 3.422 \\
\hline & $\mathrm{Ho}$ & 0.485 & 0.685 & 0.800 & 0.714 & 0.571 & 0.714 & 0.685 & 0.714 & 0.657 & 0.428 & 0.685 & 0.600 & 0.644 \\
\hline & $\mathrm{He}$ & 0.426 & 0.706 & 0.653 & 0.794 & 0.669 & 0.747 & 0.783 & 0.708 & 0.825 & 0.373 & 0.732 & 0.738 & 0.679 \\
\hline & 1-Ho/He & -0.138 & 0.030 & -0.225 & 0.101 & 0.146 & 0.044 & 0.125 & -0.008 & 0.204 & -0.147 & 0.064 & 0.187 & 0.031 \\
\hline & $F_{I S}$ & -0.142 & 0.030 & -0.255 & 0.102 & 0.148 & 0.044 & 0.101 & -0.008 & 0.206 & -0.162 & 0.064 & 0.190 & 0.026 \\
\hline & PHWE & $0.385^{\mathrm{NS}}$ & $0.265^{\mathrm{NS}}$ & $0.011^{\mathrm{NS}}$ & $0.038^{\mathrm{NS}}$ & $0.124^{\mathrm{NS}}$ & $0.262^{\mathrm{NS}}$ & $0.098^{\mathrm{NS}}$ & $0.002^{\mathrm{NS}}$ & $0.022^{\mathrm{NS}}$ & $0.340^{\mathrm{NS}}$ & $0.290^{\mathrm{NS}}$ & $0.259^{\mathrm{NS}}$ & ----- \\
\hline \multirow{8}{*}{ THW } & $\mathrm{Na}$ & 3.000 & 5.000 & 3.000 & 4.000 & 5.000 & 4.000 & 6.000 & 3.000 & 7.000 & 3.000 & 4.000 & 4.000 & 4.250 \\
\hline & $A r$ & 3.000 & 5.000 & 3.000 & 4.000 & 5.000 & 4.000 & 6.000 & 3.000 & 7.000 & 3.000 & 4.000 & 4.000 & 4.250 \\
\hline & Nae & 2.283 & 4.909 & 2.657 & 3.810 & 4.069 & 3.746 & 5.030 & 2.845 & 5.946 & 1.949 & 3.751 & 3.576 & 3.714 \\
\hline & $\mathrm{Ho}$ & 0.457 & 0.685 & 0.628 & 0.685 & 0.714 & 0.714 & 0.657 & 0.600 & 0.742 & 0.400 & 0.657 & 0.657 & 0.633 \\
\hline & $\mathrm{He}$ & 0.570 & 0.807 & 0.632 & 0.748 & 0.765 & 0.743 & 0.812 & 0.658 & 0.843 & 0.494 & 0.744 & 0.730 & 0.712 \\
\hline & 1-Ho/He & 0.198 & 0.151 & 0.006 & 0.084 & 0.066 & 0.039 & 0.191 & 0.088 & 0.120 & 0.190 & 0.117 & 0.100 & 0.112 \\
\hline & $F_{I S}$ & 0.201 & 0.129 & 0.007 & 0.085 & 0.046 & 0.040 & 0.194 & 0.055 & 0.121 & 0.193 & 0.118 & 0.072 & 0.105 \\
\hline & PHWE & $0.005^{\mathrm{NS}}$ & $0.001^{*}$ & $0.608^{\mathrm{NS}}$ & $0.002^{\mathrm{NS}}$ & $0.063^{\mathrm{NS}}$ & $0.084^{\mathrm{NS}}$ & $0.011^{\mathrm{NS}}$ & $0.282^{\mathrm{NS}}$ & $0.003^{\mathrm{NS}}$ & $0.000^{*}$ & $0.027^{\mathrm{NS}}$ & $0.101^{\mathrm{NS}}$ & ----- \\
\hline \multirow{8}{*}{ SHW } & $\mathrm{Na}$ & 2.000 & 5.000 & 3.000 & 4.000 & 4.000 & 4.000 & 5.000 & 3.000 & 6.000 & 2.000 & 3.000 & 4.000 & 3.750 \\
\hline & $A r$ & 2.000 & 5.000 & 3.000 & 4.000 & 4.000 & 4.000 & 5.000 & 3.000 & 6.000 & 2.000 & 3.000 & 4.000 & 3.750 \\
\hline & Nae & 1.90 & 3.480 & 2.948 & 3.27 & 3.085 & 3.194 & 4.090 & 2.976 & 4.351 & 1.960 & 2.825 & 3.266 & 3.112 \\
\hline & Ho & 0.428 & 0.657 & 0.657 & 0.600 & 0.685 & 0.685 & 0.600 & 0.628 & 0.714 & 0.457 & 0.628 & 0.657 & 0.616 \\
\hline & $\mathrm{He}$ & 0.48 & 0.723 & 0.670 & 0.704 & 0.685 & 0.696 & 0.766 & 0.673 & 0.781 & 0.496 & 0.655 & 0.703 & 0.669 \\
\hline & 1-Ho/He & 0.108 & 0.091 & 0.019 & 0.148 & 0.000 & 0.016 & 0.216 & 0.067 & 0.086 & 0.079 & 0.041 & 0.065 & 0.078 \\
\hline & $F_{I S}$ & 0.110 & 0.072 & 0.020 & 0.150 & 0.000 & 0.016 & 0.202 & 0.068 & 0.087 & 0.081 & 0.042 & 0.04 & 0.074 \\
\hline & PHWE & $0.515^{\mathrm{NS}}$ & $0.011^{\mathrm{NS}}$ & $0.943^{\mathrm{NS}}$ & $0.024^{\mathrm{NS}}$ & $0.061^{\mathrm{NS}}$ & $0.005^{\mathrm{NS}}$ & $0.028^{\mathrm{NS}}$ & $0.231^{\mathrm{NS}}$ & $0.211^{\mathrm{NS}}$ & $0.631^{\mathrm{NS}}$ & $0.204^{\mathrm{NS}}$ & $0.357^{\mathrm{NS}}$ & ----- \\
\hline \multirow{8}{*}{ CB } & $\mathrm{Na}$ & 3.000 & 5.000 & 3.000 & 4.000 & 4.000 & 4.000 & 6.000 & 4.000 & 8.000 & 3.000 & 5.000 & 4.000 & 4.416 \\
\hline & $A r$ & 3.000 & 5.000 & 3.000 & 4.000 & 4.000 & 4.000 & 6.000 & 4.000 & 8.000 & 3.000 & 5.000 & 4.000 & 4.416 \\
\hline & Nae & 2.825 & 4.430 & 2.980 & 3.678 & 3.822 & 3.678 & 4.851 & 3.465 & 5.946 & 2.941 & 3.983 & 3.673 & 3.856 \\
\hline & Ho & 0.485 & 0.600 & 0.657 & 0.771 & 0.828 & 0.857 & 0.685 & 0.628 & 0.685 & 0.571 & 0.685 & 0.685 & 0.678 \\
\hline & $\mathrm{He}$ & 0.655 & 0.785 & 0.674 & 0.738 & 0.749 & 0.738 & 0.805 & 0.721 & 0.843 & 0.669 & 0.759 & 0.738 & 0.739 \\
\hline & 1-Ho/He & 0.260 & 0.235 & 0.025 & -0.044 & -0.105 & -0.161 & 0.149 & 0.129 & 0.187 & 0.146 & 0.097 & 0.071 & 0.082 \\
\hline & $F_{I S}$ & 0.262 & 0.221 & 0.026 & -0.045 & -0.108 & -0.163 & 0.150 & 0.131 & 0.165 & 0.148 & 0.099 & 0.049 & 0.077 \\
\hline & PHWE & $0.000^{*}$ & $0.027^{\mathrm{NS}}$ & $0.930^{\mathrm{NS}}$ & $0.186^{\mathrm{NS}}$ & $0.075^{\mathrm{NS}}$ & $0.009^{\mathrm{NS}}$ & $0.11^{\mathrm{NS}}$ & $0.000 *$ & $0.016^{\mathrm{NS}}$ & $0.000^{*}$ & $0.077^{\mathrm{NS}}$ & $0.373^{\mathrm{NS}}$ & ----- \\
\hline \multirow{8}{*}{ TB } & $\mathrm{Na}$ & 2.000 & 6.000 & 3.000 & 4.000 & 5.000 & 4.000 & 7.000 & 3.000 & 7.000 & 3.000 & 4.000 & 4.000 & 4.333 \\
\hline & $A r$ & 2.000 & 6.000 & 3.000 & 4.000 & 5.000 & 4.000 & 7.000 & 3.000 & 6.971 & 3.000 & 4.000 & 4.000 & 4.330 \\
\hline & Nae & 1.942 & 5.147 & 2.689 & 3.746 & 3.926 & 3.656 & 5.361 & 2.743 & 5.396 & 2.340 & 3.388 & 3.816 & 3.679 \\
\hline & $\mathrm{Ho}$ & 0.542 & 0.657 & 0.742 & 0.685 & 0.771 & 0.771 & 0.800 & 0.771 & 0.742 & 0.371 & 0.685 & 0.685 & 0.685 \\
\hline & $\mathrm{He}$ & 0.492 & 0.817 & 0.637 & 0.743 & 0.756 & 0.737 & 0.825 & 0.644 & 0.826 & 0.581 & 0.715 & 0.748 & 0.710 \\
\hline & 1-Ho/He & -0.102 & 0.196 & -0.165 & 0.078 & -0.02 & -0.046 & 0.030 & -0.197 & 0.102 & 0.361 & 0.042 & 0.084 & 0.030 \\
\hline & $F_{I S}$ & -0.104 & 0.198 & -0.213 & 0.079 & -0.021 & -0.082 & 0.031 & -0.200 & 0.103 & 0.341 & 0.042 & 0.051 & 0.019 \\
\hline & PHWE & $0.536^{\mathrm{NS}}$ & $0.018^{\mathrm{NS}}$ & $0.349^{\mathrm{NS}}$ & $0.786^{\mathrm{NS}}$ & $0.303^{\mathrm{NS}}$ & $0.417^{\mathrm{NS}}$ & $0.008 *$ & $0.154^{\mathrm{NS}}$ & $0.090^{\mathrm{NS}}$ & $0.017^{\mathrm{NS}}$ & $0.989^{\mathrm{NS}}$ & $0.870^{\mathrm{NS}}$ & ----- \\
\hline
\end{tabular}


Table 3. Pairwise population differentiation (above diagonal) and genetic distance (below diagonal) across all the loci between the wild populations of $C$. mrigala

\begin{tabular}{lcccccc}
\hline Populations & BHW & KHW & THW & SHW & CB & TB \\
\hline BHW & ------ & $0.0482^{*}$ & $0.0261^{*}$ & $0.0240^{*}$ & $0.0244^{*}$ & $0.0250^{*}$ \\
KHW & 0.1571 & ------ & 0.0503 & $0.0360^{*}$ & $0.0356^{*}$ & 0.0577 \\
THW & 0.1074 & 0.1640 & ----- & $0.0335^{*}$ & $0.0278^{*}$ & $0.0203^{*}$ \\
SHW & 0.0903 & 0.1126 & 0.1140 & ------ & $0.0325^{*}$ & $0.0446^{*}$ \\
CB & 0.1079 & 0.1275 & 0.1193 & 0.1146 & ---- & $0.0151^{*}$ \\
TB & 0.1021 & 0.1832 & 0.0896 & 0.1415 & 0.0792 & ------ \\
\hline
\end{tabular}

*Significant at $p<0.05$

Table 4. Analysis of molecular variance (AMOVA) for the wild populations of $C$. mrigala

\begin{tabular}{lrrrr}
\hline Source of variation & df & SS & Variance components & \% variation \\
\hline Among populations & 5 & 341.824 & 0.73368 & 4.72 \\
Among individuals within populations & 204 & 3469.457 & 2.19643 & 14.13 \\
Within individuals & 210 & 2649.000 & 12.61429 & 81.15 \\
\hline
\end{tabular}

Table 5. Analysis of genetic bottleneck for the $C$. mrigala populations

\begin{tabular}{lccc|ccc}
\hline Populations & \multicolumn{3}{c}{ Sign test } & \multicolumn{3}{c}{ Wilcoxon test } \\
\cline { 2 - 7 } & IAM & TPM & SMM & IAM & TPM & SMM \\
\hline BHW & $0.000688^{*}$ & $0.001489^{*}$ & $0.001488^{*}$ & $0.000122^{*}$ & $0.000122^{*}$ & $0.000122^{*}$ \\
KHW & $0.000534^{*}$ & $0.001170^{*}$ & $0.001083^{*}$ & $0.000122^{*}$ & $0.000122^{*}$ & $0.000122^{*}$ \\
THW & $0.000816^{*}$ & $0.001681^{*}$ & $0.001924^{*}$ & $0.000122^{*}$ & $0.000122^{*}$ & $0.000122^{*}$ \\
SHW & $0.000542^{*}$ & $0.001183^{*}$ & $0.001293^{*}$ & $0.000122^{*}$ & $0.000122^{*}$ & $0.000122^{*}$ \\
CB & $0.000797^{*}$ & $0.001883^{*}$ & $0.001964^{*}$ & $0.000122^{*}$ & $0.000122^{*}$ & $0.000122^{*}$ \\
TB & $0.000660^{*}$ & $0.001412^{*}$ & $0.001564^{*}$ & $0.000122^{*}$ & $0.000122^{*}$ & $0.000122^{*}$ \\
\hline
\end{tabular}

*Significant at $p<0.05$

3.750 in SHW population to 4.416 in CB population. The mean values of effective number of alleles (Nae) was observed in a range from 3.112 to 3.856 . The average values of observed heterozygosity $(\mathrm{Ho})$ ranged from 0.563 to 0.685 and those of expected heterozygosity $(\mathrm{He}$ ) from 0.669 to 0.739 . The highest value of $H o$ was measured in TB and the lowest in the BHW population. Whereas, the lowest value of $H e$ was in SHW and highest in CB population. The range of coefficient of inbreeding $\left(F_{I S}\right)$ values was observed from 0.019 to 0.184 . After applying multiple test correction, 9 out of 72 tests were significantly deviated from $H W E$ at $P<0.05$.

Genetic structure: The genetic differentiation $\left(F_{S T}\right)$ was found low-to-moderate among the wild populations of $C$. mrigala. The highest value (0.0577) of genetic differentiation was observed between the KHW and TB population pair while, the lowest (0.0151) between CB-TB pair (Table 3). Among the pairs of populations, the genetic distance values showed considerable differences in magnitude at $P<0.05$. The genetic distance between the population pair of KHW and TB was found to be maximum (0.1832) while, that of CB and TB was minimum (0.0792). The Analysis of molecular variance (AMOVA) revealed that $81.15 \%$ differentiation was contributed due to variation within individuals. While, minor variations were observed $(4.72 \%)$ among populations and among individuals within populations (14.13\%) (Table 4).
The tests for detecting genetic bottleneck under IAM, TPM and SMM mutation models detected a recent genetic bottleneck (Table 5, Fig. 2).

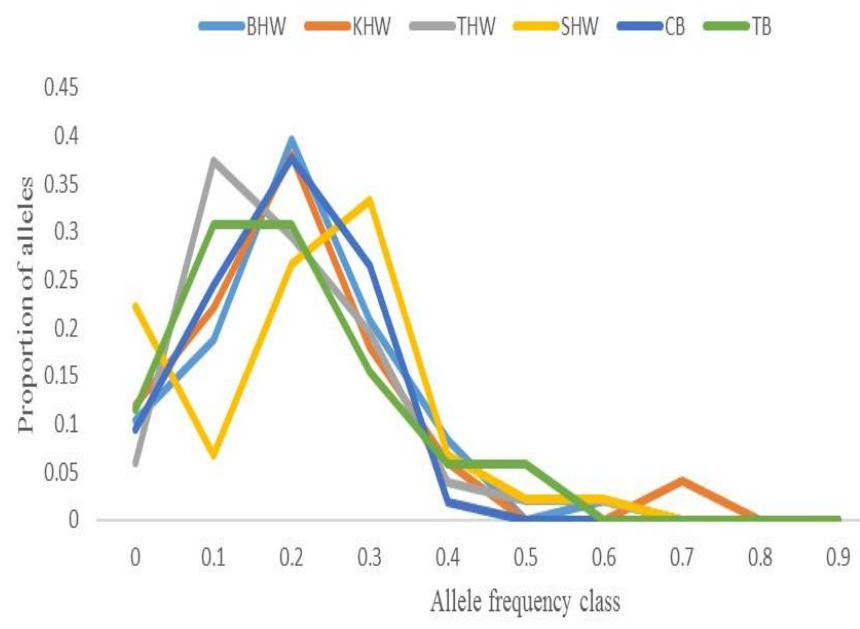

Figure 2. Proportion of allele frequencies in the wild populations of $C$. mrigala

The UPGMA dendrogram resulted in two distinct clusters, showing the close relationship between the populations in each cluster. The first cluster was further subdivided into two 
subclusters, encompassing $\mathrm{CB}, \mathrm{TB}$ and THW in first subcluster while, BHW and SHW in the other subcluster. Whereas, the second cluster did not show any further subdivision and comprised only KHW population (Fig. 3). The genetic relationship among the wild populations of $C$. mrigala was further investigated by STRUCTURE grouping algorithm method. The consistent results were obtained over 7 independent runs and the maximum estimated $\log$ likelihood mean value and delta $\mathrm{k}$ value was observed for $\mathrm{K}=2$ (Fig. 4).
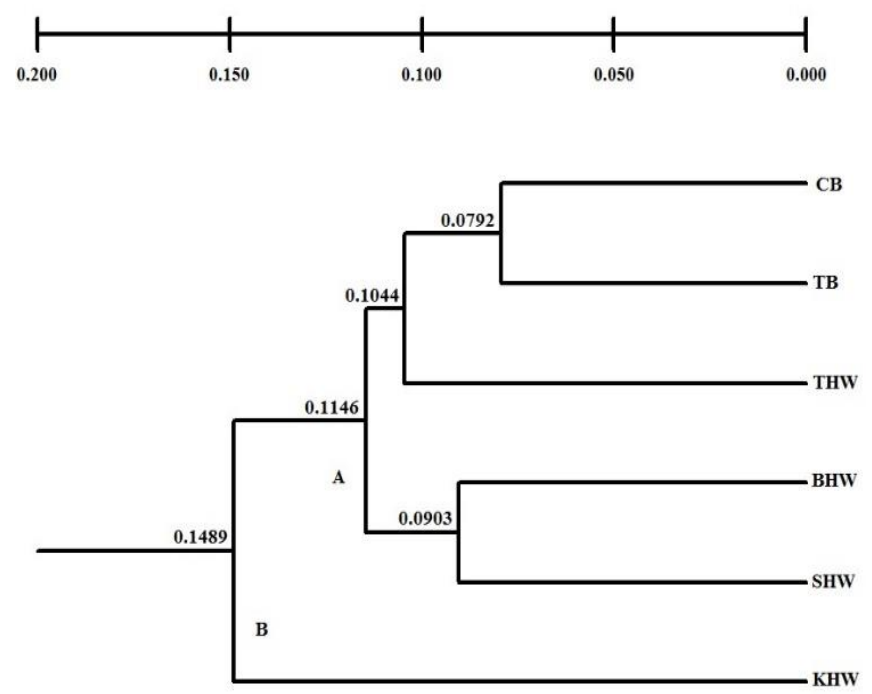

Figure 3. UPGMA dendrogram among the wild populations of $C$. mrigala based on Nei's standard genetic distance

\section{DISCUSSION}

Despite having large biodiversity of freshwater fishes in Pakistan, there are limited studies available on the genetic status of natural populations. The fish, Cirrhinus mrigala is an important freshwater fish species of Pakistan significantly contributing to the economy of the country but facing a decline in its population due to human interventions as well as captive breeding programs. Few studies are available on the genetic status of this species (Lal et al., 2004; Das et al., 2005; Chauhan et al., 2007; Masih et al., 2014). However, this study is the first to report the extent of genetic variability in wild populations of $C$. mrigala from Punjab province, Pakistan.

Genetic diversity: In this study, moderate level of genetic diversity was observed in the wild populations of $C$. mrigala. The observed number of alleles at various microsatellite loci extended from 2 to 8 . The maximum values of observed number of alleles, allelic richness and effective number of alleles was examined in $\mathrm{CB}$ population while, the lowest in SHW population.

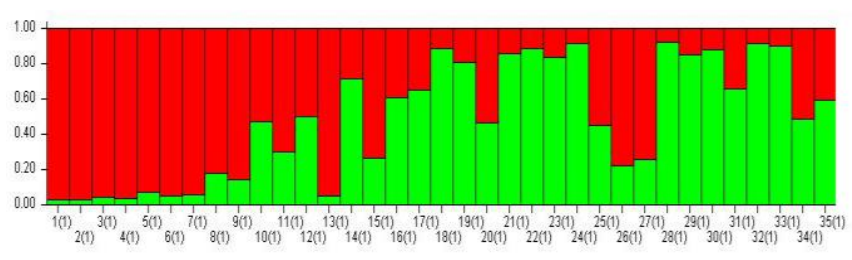

BHW

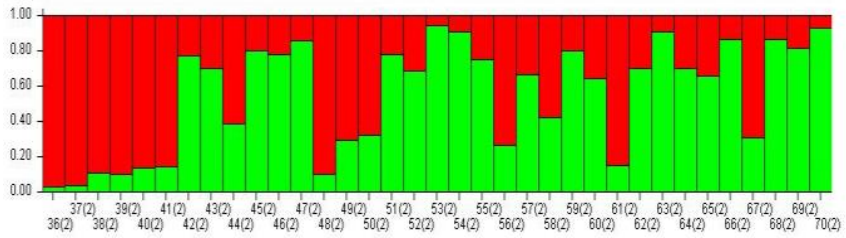

KHW

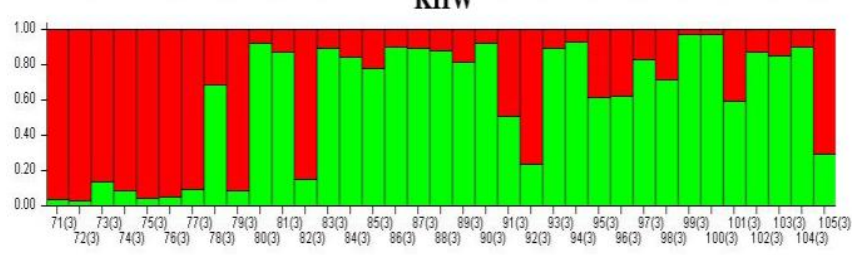

THW

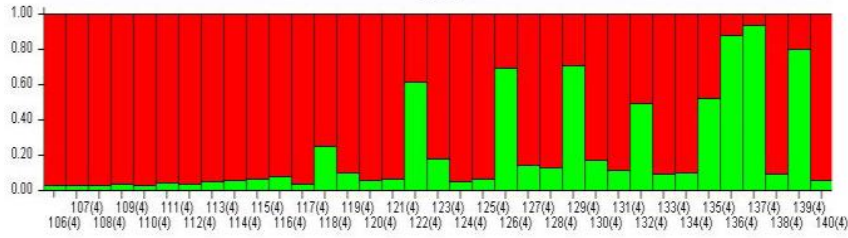

SHW

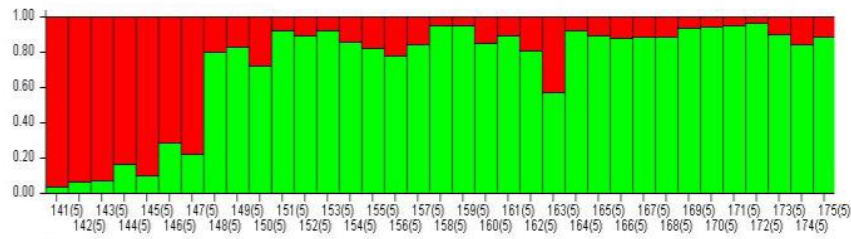

CB

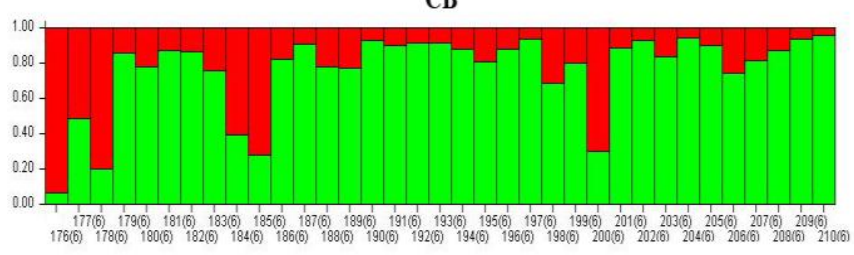

TB

Figure 4. Genetic structuring between the wild populations of $C$. mrigala as identified by STRUCTURE. The individuals are represented by vertical bars and each column is representing one individual. The distinct colors of the columns indicate the estimated probability of belonging to one or the other population. Different colors in the same individual represents the percentage of shared genome. 
Allelic diversity and heterozygosity are the two key components which should be considered in studies related to genetic variations. However, prior to heterozygosity, the most important is the number of alleles $(\mathrm{Na})$ which is more influenced by the effective size of population and strongly depends on the past evolutionary history of a population (Nei et al., 1975). Moreover, the observed number of alleles as well as their frequency are influenced by the sample size and the molecular marker system used (Maqsood and Ahmad, 2017). The range of average values of observed heterozygosity was measured from 0.563 to 0.685 . Whereas, the average values of expected heterozygosity ranged from 0.669 to 0.739 , which were higher than the values of observed heterozygosity.

Comparable results about moderate level of heterozygosity were reported in wild populations of Labeo calbasu (Singh et al., 2012), Gara rufa (Shabani et al., 2013) and Labeo rohita (Tonny et al., 2014) by employing microsatellite markers. In the case of wild fish, the $\mathrm{He}$ is directly related to the effective size $(\mathrm{Ne})$ of the population. The occurrence of homozygosity at a locus or population facing genetic bottleneck could be attributed to the excess of $\mathrm{He}$ and smaller values of $\mathrm{Ho}$ in fish populations (Pemberton et al., 1995). The reason behind lower $\mathrm{Ho}$ as compared to the $\mathrm{He}$ might also be postulated by the stress due to overfishing of natural resources, deterioration in breeding environments and sampling error.

Positive mean values of $1-\mathrm{Ho} / \mathrm{He}$ and $F_{I S}$ were found in all the populations. Related inferences were presented by Hasanat $e t$ al. (2015) in wild and captive populations of Cirrhinus cirrhosus which revealed that all the studied populations were deficient in heterozygosity. Biba et al. (2017) also found positive values of inbreeding coefficient in natural populations of Cyprinus carpio. After applying multiple test correction, a total of 9 out of 72 tests deviated significantly from Hardy-Weinberg equilibrium and the deviated loci are considered to be heterozygote deficient. Non-random sampling, inbreeding, Wahlund effect/intra-population structure, genetic drift, overexploitation and a combination of all the aforementioned factors are presumably responsible for the deviation from HWE (Bergh and Getz, 1989; Gopalakrishnan et al., 2009; Abbas et al., 2010).

Genetic structure: Reliable estimates of population differentiation are required for better understanding the connectivity among populations and to develop conservation strategies. The genetic differentiation can be divided into different levels viz; weak (0.00-0.05), moderate (0.50-0.150), strong (0.150-0.250) and above 0.250 indicates very high level of genetic differentiation (Wright, 1978). Based on the above mentioned assumptions, low-to-moderate level of genetic differentiation was found among the wild populations of $C$. mrigala. The highest value of genetic differentiation was observed as 0.0577 between the population pair of KHW and TB and the lowest as 0.0151 between the CB-TB pair. The minimum value shows a close relationship with the sharing of genetic material while, the maximum value specifies that the populations are genetically isolated with less sharing of alleles. The population genetic structure of freshwater fish is reinforced by the distribution of their riverine systems (Nagarajan et al., 2006). The genetic differentiation is also influenced by various physical and biological factors including overexploitation, habitat fragmentation, hydrological alterations, contamination of native gene pool (inbreeding and introgression) and bottleneck effect (Koizumi et al., 2006). By using microsatellite markers, Ahmed and Abbas (2018) found the same pattern of genetic differentiation in wild and hatchery stocks of Catla catla in Punjab province, Pakistan. In contrast, Chauhan et al. (2007) and Nesa et al. (2018) evaluated low level of genetic structuring in wild populations of Cirrhinus mrigala and Cirrhinus cirrhosus, respectively. The analysis for genetic bottleneck revealed a recent genetic bottleneck under various mutation models. The evidences of genetic bottleneck in natural populations despite having moderate genetic diversity could be related to the pre-bottleneck size of the populations being large enough or the populations are subjected to demographic recovery. Furthermore, the overexploitation, habitat degradation and population fragmentation have also been the possible reason of bottleneck in many natural populations.

The AMOVA revealed that most of the variation lied within the individuals of wild populations. Similar pattern of genetic structuring was observed by Qadeer and Abbas (2017) in riverine Labeo rohita inferred from microsatellite markers. The UPGMA dendrogram showed two main clusters comprising the $\mathrm{CB}, \mathrm{TB}$, THW, BHW and SHW in first cluster excluding KHW population alone in the second cluster. The reasons behind such kind of homogenization between the natural populations could be attributed to the open water stocking of farmed fish from the same source, aquaculture practices and natural calamities. The genetic relationship was further investigated by STRUCTURE grouping algorithm method which proposed the presence of two distinct genetic clusters. The maximum estimated log likelihood mean value and delta $k$ value was observed for $K=2$. The accurate determination of the number of groups present among populations is dependent on the total number of individuals genotyped and the number of markers utilized. Evanno et al. (2005) described that calculating delta $\mathrm{k}$ by using a minimum of five microsatellite markers can allow the precise determination of the actual number of groups.

For the sustainable management of freshwater fish species, it is a prerequisite to make persistent use of available resources and to maintain a high level of genetic variations. The most suitable approach is to regularly assess the fish stocks in natural waters, avoid the overexploitation of fish populations, setting up adequate number of brooders in fish hatcheries, discourage the stocking of natural waters with genetically depauperated fish seeds and improve the breeding and feeding grounds by regulating the riverine water flow. 


\section{Amjad \& Abbas}

\section{REFERENCES}

Abbas, K., X.Y. Zhou, Y. Li, Z.X. Gao and W.M. Wang. 2010. Microsatellite diversity and population genetic structure of Yellowcheek, Elopichthys bambusa (Cyprinidae) in the Yangtze River. Biochem. Syst. Ecol. 38:806-812.

Abdul-Muneer, P.M. 2014. Application of microsatellite markers in conservation genetics and fisheries management: Recent advances in population structure analysis and conservation strategies. Genet. Res. Int. 2014:1-11.

Ahmed, T. and K. Abbas. 2018. Patterns of genetic variability in natural and hatchery populations of Catla catla based on microsatellite DNA markers. Pak. J. Agric. Sci. 55:929-939.

Backer, J., P. Bentzen and P. Moran. 2002. Molecular markers distinguish coastal cutthroat trout from coastal rainbow trout/ steelhead and their hybrids. Trans. Am. Fish. Soc. 131: 404-417.

Banerjee, T., K.D. Raj and V. Misra. 2008. Conservation of natural fish population. In Proceedings of Taal 2007: The 12th World Lake Conference, pp. 562-567.

Banks, S.C., G.J. Cary, A.L. Smith, I.D. Davies, D.A. Driscoll, A.M. Gill and R. Peakall. 2013. How does ecological disturbance influence genetic diversity? Trends Ecol. Evol. 28:670-679.

Bergh, M.O. and W.M. Getz. 1989. Stability and harvesting of competing populations with genetic variation in life history strategy. Theor. Popul. Biol. 113:939-965.

Biba, A., A. Hoda, V. Bozgo and S. Mali. 2017. Genetic diversity of Cyprinus carpio of natural lakes in Albania estimated by microsatellite loci. Endocytobiosis Cell Res. 28:1-8.

Chauhan, T., K.K. Lal, V. Mohindra, R.K. Singh, P. Punia, A. Gopalakrishnan and W.S. Lakra. 2007. Evaluating genetic differentiation in wild populations of the Indian major carp, Cirrhinus mrigala (Hamilton-Buchanan, 1882): evidence from allozyme and microsatellite markers. Aquaculture 269:135-149.

Ciftci, Y. and I. Okumus. 2002. Fish population genetics and applications of molecular markers to fisheries and aquaculture: basic principles of fish population genetics. Turk. J. Fish. Aquat. Sci. 2:145-155.

Das, P., A. Barat, P.K. Meher, P.P. Ray and D. Majumdar. 2005. Isolation and characterization of polymorphic microsatellites in Labeo rohita and their cross-species amplification in related species. Mol. Ecol. Notes 5:231233.

Earl, D.A. and B.M. Vonholdt. 2012. STRUCTURE HARVESTER: a website and programme for visualizing STRUCTURE output and implementing the Evanno method. Conserv. Genet. Resour. 4:359-361.
Evanno, G., S. Regnaut and J. Goudet. 2005. Detecting the number of clusters of individuals using the software STRUCTURE: a simulation study. Mol. Ecol. 14:26112620.

Excoffier, L., G. Laval and S. Schneider. 2005. Arlequin (version 3.0): An integrated software package for population genetics data analysis. Evolut. Bioinformat. $1: 47-50$

Falush, D., M. Stephens and J.K. Pritchard. 2003. Inference of population structure: Extensions to linked loci and correlated allele frequencies. Genetics 164:1567-1587.

FAO, 2004. FAO year book of fisheries statistics. Aquaculture Production, vol. 90/2. Food and Agriculture Organization of United Nations, Rome, Italy.

FAO, 2006. FAO yearbook. Fishery and aquaculture statistics, FAO, Rome, Italy. p. 26.

Gopalakrishnan, A., K.K. Musammilu, V.S. Basheer, L. John, K.G. Padmakumar, K.K. Lal, V. Mohindra, P. Punia, K. Dinesh, M. Hashim, A.G. Ponniah and W.S. Lakra. 2009. Low genetic differentiation in the populations of the Malabar carp Labeo dussumierias revealed by allozymes, microsatellites and RAPD. Asian Fish Sci. 22:359-391.

Goudet, J. 2002. FSTAT Version 2.9.3.2. A programme to estimate and test gene diversities and fixation indices. Institute of Ecology, University of Lausanne, Switzerland.

Hasanat, M.A., M.F.A. Mollah and M.S. Alam. 2015. Microsatellite DNA marker analysis revealed low levels of genetic variability in the wild and captive populations of Cirrhinus cirrhosus (Hamilton) (Cyprinidae: Cypriniformes). Br. Biotechnol. J. 5:206-215.

Kawecki, T.J. and D. Ebert. 2004. Conceptual issues in local adaptation. Ecol. Lett. 7:1225-1241.

Koizumi, I.Y., S. Amamoto and K. Maekawa. 2006. Decomposed pairwise regression analysis of genetic and geographic distances reveals a metapopulation structure of stream-dwelling Dolly Varden charr. Mol. Ecol. 15:3175-3189.

Lal, K.K., T. Chauhan, A. Mandal, R.K. Singh, L. Khulbe, A.G. Ponniah and V. Mohindra. 2004. Identification of microsatellite DNA markers for population structure analysis in Indian major carp, Cirrhinus mrigala. J. Appl. Ichthyol. 20:87-91.

Maqsood, H.M. and S.M. Ahmad. 2017. Advances in molecular markers and their applications in aquaculture and fisheries. Genet. Aqua. Organ. 1:1-15.

Masih, P., R.K. Luhariya, R. Das, A. Gupta, V. Mohindra, R.K. Singh, R. Srivastava, U.K. Chauhan, J.K. Jena and K.K. Lal. 2014. Cross-priming of microsatellite loci in subfamily Cyprininae (family Cyprinidae): their utility in finding markers for population genetic analysis in three Indian major carps. Mol. Biol. Rep. 41:5187-5197.

Miller, M.P. 1997. Tools for Population Genetic Analyses (TFPGA) V 1.3: A Windows Program for the Analysis of 
Allozyme and Molecular Genetic Data. Flagstaff: Northern Arizona, University.

Nagarajan, M., M.A. Haniffa, A. Gopalakrishnan, V.S. Basheer and A. Muneer. 2006. Genetic variability of Channa punctatus populations using randomly amplified polymorphic DNA. Aquacult. Res. 37:1151-1155.

Nei, M. 1972. Genetic distance between populations. Am. Nat. 106:283-292.

Nei, M., T. Maruyama and R. Chakraborty. 1975. The bottleneck effect and genetic variability in populations. Evolution 29: 1-10.

Nesa, N.U., A.A. Faroque, M.R.I. Sarder and M.F.A. Mollah. 2018. Assessment of genetic structure of wild populations of Mrigal carp, Cirrhinus cirrhosus by microsatellite DNA markers. Aquacult. Res. 49:39193925.

Oosterhout, C.V., W.F. Hutchinson, D.P.M. Wills and P. Shipley. 2004. MICRO-CHECKER: software for identifying and correcting genotyping errors in microsatellite data. Mol. Ecol. Notes 4:535-538.

Pemberton, J.M., J. Slate, D.R. Bancroft and J.R. Barrett. 1995. Nonamplifying alleles at microsatellite loci: a caution for parentage and population studies. Mol. Ecol. 4:249-252.

Piry, S., G. Luikart, J.M. Cornuet. 1999. BOTTLENECK: A computer program for detecting recent reductions in the effective populations size using allele frequency data. J. Heredity 90:502-503.

Pritchard, J.K., M. Stephens and P. Donnelly. 2000. Inference of population structure using multi locus genotype data. Genetics 155:945-959.

Qadeer, I. and K. Abbas. 2017. Microsatellite markers based genetic structure of Rohu (Labeo rohita) in selected riverine populations of Punjab, Pakistan. Pak. J. Agric. Sci. 54:865-872.

Rasmussen, C., C.O. Ostberg, D.R. Clifton, J.L. Holloway and R.J. Rodriguez. 2003. Identification of a genetic marker that discriminates ocean-type and stream-type Chinook Salmon in the Columbia River basin. Trans. Am. Fish. Soc. 132:131-142.

Rocha-Olivares, A., H.G. Moser and J. Stannard. 2000. Molecular identification and description of pelagic young of the rockfishes Sebastes constellatus and Sebastes ensifer. Fish. Bull. 98:353-363.

Sambrook, J. and D.W. Russell. 2001. Molecular cloning: a laboratory manual. $3^{\text {rd }}$ Ed. Cold Spring Harbor Laboratory Press, New York, USA.

Sanguinetti, C.J., E.D. Neto and A.J.G. Simpson. 1994. Rapid silver staining and recovery of PCR products separated on polyacrylamide gels. Biotechniques 17:915-919.

Shabani, A., G. Askari and A. Moradi. 2013. Genetic variation of Garra rufa fish in Kermanshah and Bushehr provinces, Iran, using SSR microsatellite markers. Mol. Biol. Res. Commun. 2:81-88.

Singh, R.K., K.K. Lal, V. Mohindra, P. Punia, R.S. Sah, R. Kumar, A. Gupta, R. Das, W.S. Lakra and S. Ayyappan. 2012. Genetic diversity of Indian major carp Labeo calbasu (Hamilton, 1822) populations inferred from microsatellite loci. Biochem. Syst. Ecol. 44:307-316.

Tonny, U.S., A.A. Faroque, R.I. Sarder and F.A. Mollah. 2014. Assessment of genetic variation of wild rohu Labeo rohita (Hamilton 1822) populations using microsatellite markers. African J. Fish. Sci. 2:168-175.

Weir, B.S. and C.C. Cockerham. 1984. Estimating F statistics for the analysis of population structure. Evolution 38:1358-1370.

Wright, S. 1978. Evolution and the genetics of population's variability within and among natural populations, $2^{\text {nd }} E d$. University of Chicago Press, Chicago.

Yeh, F.C., R.C. Yang and T. Boyle. 1999. POPGENE V. 1.31: Microsoft windows-based free software for population genetic analysis. University of Alberta, Edmonton. 